Vol.01/ No. 02

Pages: 103-112

https://www.irojournals.com/iroeea

DOI: https://doi.org/10.36548/jeea.2019.2.005

\title{
DESIGN OF INDUSTRIAL ROBOT FOR METAL DRILLING
}

\author{
Dr. A. Dinesh Kumar, \\ Computer Science and Engineering, \\ Koneru Lakshmaiah Education Foundation, \\ Andra Pradesh, India. \\ Email: adinesh@kluniversity.in
}

\begin{abstract}
The latest advancements in the programming techniques combined with the novel visionary and the motion technologies intensifying the possibility of the robotic applications. Nowadays the use of Robots in the industries mainly for the purpose of drilling, grinding and grating are very much increased. But due to the measurement variation's along the different axes based on the physical and the mechanical properties of the material and the stiffness problems found in the Robots there prevails certain errors causing the modifications in the positioning. So the proposed process in the paper concentrates on the enhancing the stiffness of the robots and bring down the labors in the drilling process in order to have an optimized output at a reduced cost. The proposed design shows improvement in the accuracy and the efficiency of the robot working with the minimized rejection loss and the cost of the end product.
\end{abstract}

Keywords: Robotics, Robotic drilling, Accuracy, Cost, Efficiency

\section{INTRODUCTION}

The Robots are emerging to work along the human side to develop a well structure organization in the future. Nowadays to improve the perfection in the job, reduce the man power involvement in the job and to avoid the unnecessary fatalities in the industry's most of the large scale industries have changed to the utilization of the robotics for performing the critical jobs such as drilling, milling and grinding. More over the financial reasons also prevails as a main reason for encouraging the robotics in the industries to compete with the machines that are assisted with manpower in the industries.

ISSN: 2582-3051 
Journal of Electrical Engineering and Automation (EEA) (2019)

Vol.01/ No. 02

Pages: 103-112

https://www.irojournals.com/iroeea

DOI: https://doi.org/10.36548/jeea.2019.2.005

The Robot functions as a replacement to the humans and is employed in a wide range of applications that holds high risk for the human lives. They were often viewed as the human shape dolls that and assist the humans in the regular activities. The word robot came into use from the play "Rossum's Universal robot" that was created by Karl Capeck. The Robot is a Czech word meaning "mechanical slave developed against humans"

Despites its usages in the form of the vivid images in the animated comics and the science fictions, they found they use even in the real life applications such as factories performing repetitive tasks such as the assembling, painting, palletizing, cutting, welding etc. Those Robots were called the industrial, later in the year 1996 and 1997 the Honda developed a humanoid robotics P2 and P3 that could walk and perform advanced operations respectively. The Sony also developed a "SDR-3X" later in 2000 a small autonomous humanoid robot that uses the robot architecture that resembles the robot dog AIBO.

The drilling robotics is a very complex task, as its process and the behavior modelling are very complex, as there is different active area and varying set of parameters associated with the drilling process. All these functions pressure the industrial robots and affect the accuracy in the drilling process by changing the positions and the stiffness of the process. It was found that the static and the dynamic distortion occurred depending on the stress frequency as listed in the table. 1 below.

\begin{tabular}{|c|c|c|c|}
\hline $\begin{array}{c}\text { Dynamic } \\
\text { Errors }\end{array}$ & $\begin{array}{c}\text { Frequency } \\
(\mathrm{Hz})\end{array}$ & Statistic Errors & $\begin{array}{c}\text { Error in (micro } \\
\mathrm{m})\end{array}$ \\
\hline Drive Errors & 100 & & 10 \\
\hline $\begin{array}{c}\text { Natural } \\
\text { Oscillations } \\
\text { of the } \\
\text { kinematics }\end{array}$ & 50 & & $10^{1}$ \\
\hline $\begin{array}{c}\text { Elastic twist } \\
\text { by process } \\
\text { forces and } \\
\text { inertia forces }\end{array}$ & 10 & & $10^{2}-10^{3}$ \\
\hline & 1 & $\begin{array}{c}\text { Thermal } \\
\text { deformation }\end{array}$ & 10 \\
\hline Transfer Errors & $10^{1}$ and $10^{2}$ \\
\hline
\end{tabular}

ISSN: 2582-3051 
Journal of Electrical Engineering and Automation (EEA) (2019)

Vol.01/ No. 02

Pages: 103-112

https://www.irojournals.com/iroeea

DOI: https://doi.org/10.36548/jeea.2019.2.005

Table.1 Static and Dynamic Errors

To enhance the accuracy and the quality in drilling and eliminate the slipping while operating proposed process in the paper concentrates on the enhancing the stiffness of the robots and bring down the labors in the drilling process in order to have an optimized output at a reduced cost. The proposed design shows improvement in the accuracy and the efficiency of the robot working with the minimized rejection loss and the cost of the end product.

\section{RELATED WORKS}

The use of the robotics has been a reason for many revolutions in the industrial environment such as safety, cost and time of completion for the end product. The robotics used in the manufacturing industry to enhance the safety by sensing and controlling the process of the manufacturing for the automobile industry is put forth by the Smys, S., and G. Ranganathan et al [1] , the theory presenting the modelling and the control of the industrial robotics was explained by the author Cubero, Sam et al [2] followed by the "Mechanical design and modelling of a robotic planetary drilling system." in the same year by the author Liu, Yinghui, Brian Weinberg, and Constantinos Mavroidis et al [3]. the figure.1 below shows the conventional robotic drill system.

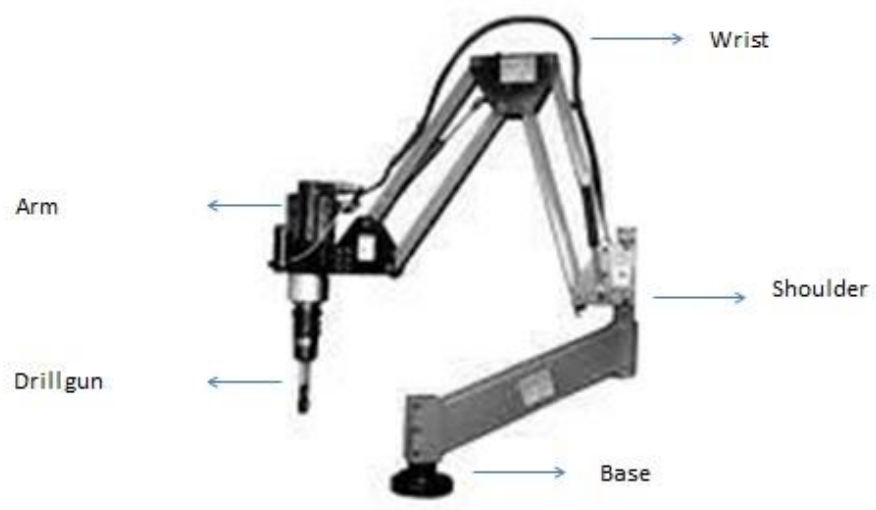

ISSN: 2582-3051 
Journal of Electrical Engineering and Automation (EEA) (2019)

Vol.01/ No. 02

Pages: 103-112

https://www.irojournals.com/iroeea

DOI: https://doi.org/10.36548/jeea.2019.2.005

Fig.1 Conventional Robotic Drill

Further the "Modelling and simulation of a SCARA robot using solid dynamics and verification by MATLAB/Simulink" was developed by the authors Alshamasin, Mahdi Salman, Florin Ionescu, and Riad Taha AlKasasbeh. et al [4] to enhance the process of identification and control. Federspil, Philipp A., Urban W. Geisthoff, Dominik Henrich, and Peter K. Plinkert et al [5] developed the robots with the first force control to handle the otoneuro surgery.

Vijayakumar, et al [6] in his paper developed the robotic electronic skin with flexibility and improved sensitivity using the sensors to protect the human skin on the fire accidents. The article by Siciliano, Bruno, Lorenzo Sciavicco, Luigi Villani, and Giuseppe Oriolo et al [7] provides the details on the robotic modelling, and planning and control and the paper by the Sciavicco, Lorenzo, and Bruno Siciliano et al [8] provides the designing of the robotics as manipulators.

The precision enhancement and the delay minimization in the telerobotics was developed by the authors Manoharan, Samuel, and Narain Ponraj et al [9] the authors Bu, Yin, Wenhe Liao, Wei Tian, Jin Zhang, and Lin Zhang et al [10] provides the "Stiffness analysis and optimization in robotic drilling application." Zubrzycki, Jarosław, Antoni Świć, and Marek Opielak et al [11] in his paper proposes the "Modelling of dynamic system characteristics of deep hole drilling process with tools about flexible stiffness." The "Modelling approaches for an ultrasonic percussion drill." was proposed by the Potthast, Christian, Jens Twiefel, and Jörg Wallaschek et al [12] in the year 2007.

The authors Sedano, Javier, Emilio Corchado, Leticia Curiel Herrera, José Ramón Villar Flecha, and Pedro Miguel Bravo et al [13] developed the two step artificial intelligence model and applied it in the pneumatic drilling process to achieve automation in it. To develop an optimized route for the drill robot the author Adam et al [14] proposed a particle swarm optimization to find the best drill route for the robots. Wang, et al [15] presented the base detection by the visual inspection for the robot system. Liu et al [16] modeled a pure percussive drill for rehabiliting the robot bridge decks automatically.

ISSN: 2582-3051 
Journal of Electrical Engineering and Automation (EEA) (2019)

Vol.01/ No. 02

Pages: 103-112

https://www.irojournals.com/iroeea

DOI: https://doi.org/10.36548/jeea.2019.2.005

\section{PROPOSED WORK}

The proposed Robotic drill is designed based on the three laws of the robotics, that the robot in action will not be harmful for the humans or work against the humans, obliges to the order of the humans and is assisted by the humans and works protecting its own existence if the protection doesn't conflict with the first and the second law. The fig. 1 below shows the framing of the proposed robotic drill.



Fig.2 Block diagram of Proposed Robotic Drill

The robotic drill in the proposed model is programmed using the pinguino pic 32 to identify the position to be drilled maintaining the perpendicularity. The program is developed manually using the C program or ASM and fed into the processor; the micro controller controls the four motors that initiate the drill operation. The motor 1 initiate the rotation of the drill chuck, the motor two takes care of the movement of the wrist, and the motor three and four takes care of the gear 1 and the gear 2 that initiate the process and the movement of the drill gun respectively.

ISSN: 2582-3051 
Journal of Electrical Engineering and Automation (EEA) (2019)

Vol.01/ No. 02

Pages: 103-112

https://www.irojournals.com/iroeea

DOI: https://doi.org/10.36548/jeea.2019.2.005

The robotic drill is comprised of several parts servo motors, Dc motors, pinguino pic 32, a wheel base and a zig bee module. The fig. 3 provides the details of the link movement and the base movement controlled by the pic 32 .

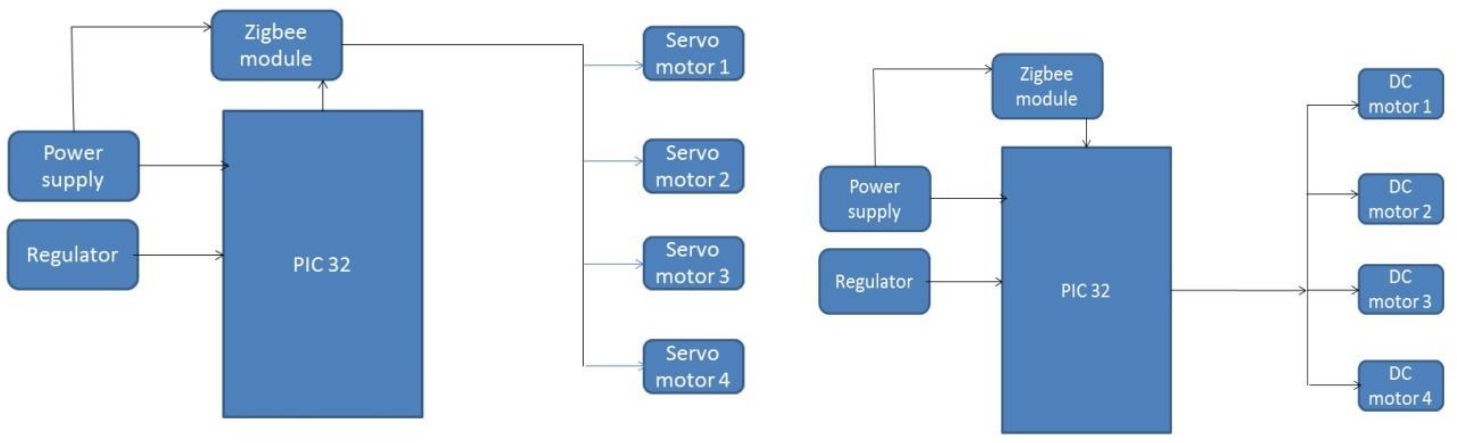

Fig. 3 link movement (left side) and the base movement (right side)

The tower pro MG995 metal gear servo motor is utilized in the control the gears in the robot, and the 1298n motor driver dual $\mathrm{H}$ Bridge is used to control the direction as well as the speed of the motor. The DIGI Zigbee 80.15.4module is utilized to provide a simple serial method of transmission and reception between the component and the pic 32 .

The entire system is controlled using the personal computer that communicates through the RF module, employing the multiplexer and the de-multiplexer to convert the parallel data to serial in the transmitter side and the serial data to parallel data in the receiver side respectively.

These Robotic drills can be used in the industries for performing accurate drilling for about 150 per minute avoiding the static and the dynamic errors that are found in the conventional robotics drill. The robot is designed with light weight objects to be of less weight and small size.

ISSN: 2582-3051 
Journal of Electrical Engineering and Automation (EEA) (2019)

Vol.01/ No. 02

Pages: 103-112

https://www.irojournals.com/iroeea

DOI: https://doi.org/10.36548/jeea.2019.2.005

\section{RESULTS}

The fig. 4 below shows the convergence graph that provides the depth drilled by the proposed robot and the conventional robot.

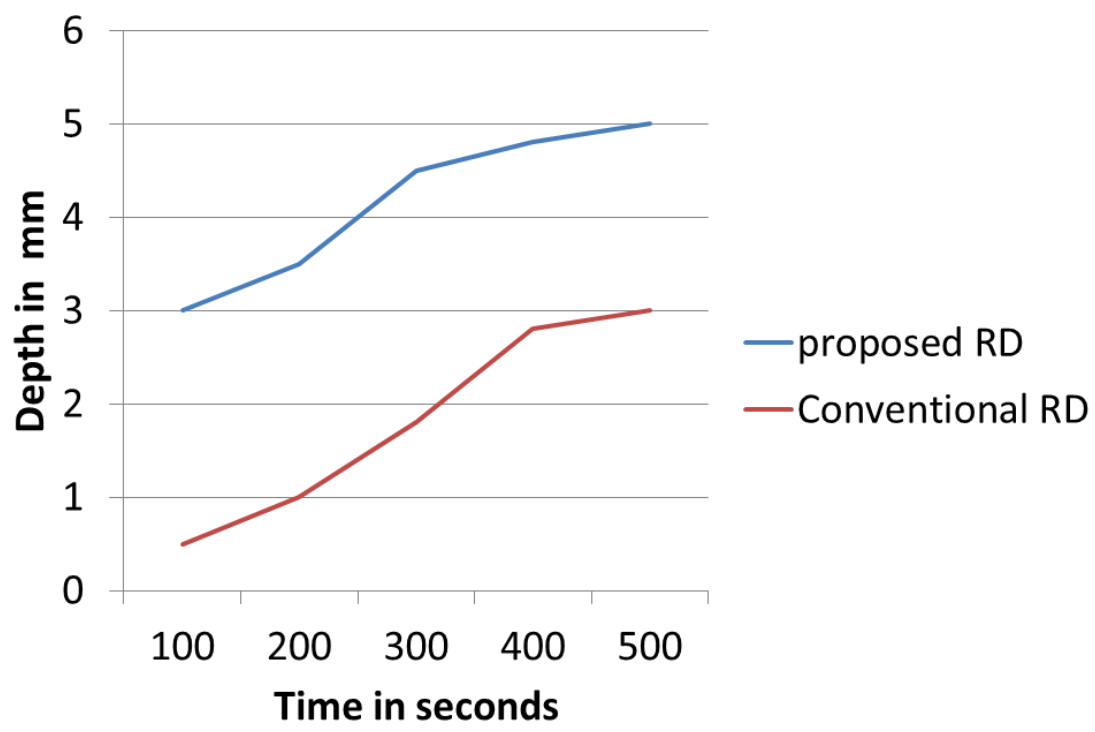

Fig.4 drilling depth

The qualitative analysis of the proposed drilling robot, the operation of the motor based on the, pay load, mass, radius, accuracy, response time, torque and throughput are analyzed and compared with the conventional robotic drilling (RD) machine. Where the pay load refers to the depth drilled by the robot. When the direction of the arm changes this affects the speed and in turn causes the changes in the throughput. The throughput refers to number of metals that that can be drilled in a second and this depends on the mass and the radius of the object. The response time refers to the time taken for the communication between the receiver and the transmitter module. The fig.5

ISSN: 2582-3051 
Journal of Electrical Engineering and Automation (EEA) (2019)

Vol.01/ No. 02

Pages: 103-112

https://www.irojournals.com/iroeea

DOI: https://doi.org/10.36548/jeea.2019.2.005

below provides the percentage of the throughput, cost and the accuracy in positioning achieved by the proposed system. The results obtained are compared with the conventional system.

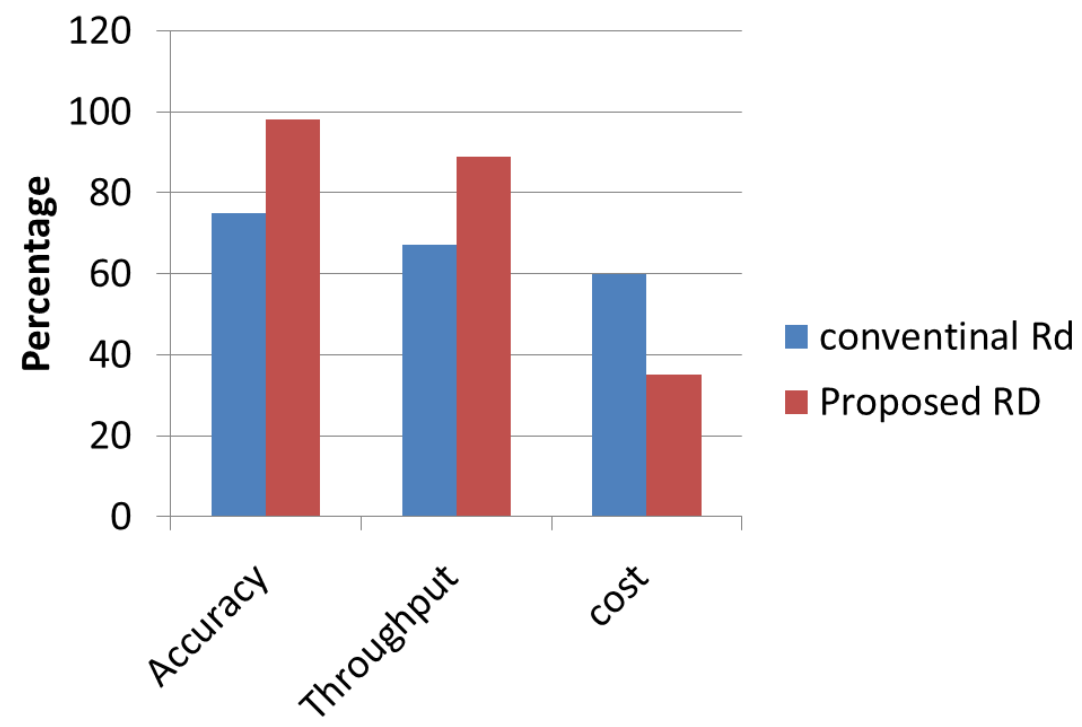

Fig. 5 comparative Analysis

\section{CONCLUSION}

The paper presents the designing of the metal drilling robot that can be used in the manufacturing industry. The linking and the base are developed using the microcontroller and the controlled by the personal computer. The programming allows having stiffness in the robot arm by accurately positioning the place to be drilled and maintain the perpendicularity. The result obtained highlights the efficiency of the proposed system against the conventional drilling robots in terms of throughput, cost and accuracy.

\section{References}

ISSN: 2582-3051 
Journal of Electrical Engineering and Automation (EEA) (2019)

Vol.01/ No. 02

Pages: 103-112

https://www.irojournals.com/iroeea

DOI: https://doi.org/10.36548/jeea.2019.2.005

[1] Smys, S., and G. Ranganathan. "ROBOT ASSISTED SENSING, CONTROL AND MANUFACTURE IN AUTOMOBILE INDUSTRY." Journal of ISMAC 1, no. 03 (2019): 180-187.

[2] Cubero, Sam. Industrial robotics: Theory, modelling and control. Pro Literatur Verlag, 2006.

[3] Liu, Yinghui, Brian Weinberg, and Constantinos Mavroidis. "Mechanical design and modelling of a robotic planetary drilling system." In ASME 2006 International Design Engineering Technical Conferences and Computers and Information in Engineering Conference, pp. 925-932. American Society of Mechanical Engineers Digital Collection, 2006.

[4] Alshamasin, Mahdi Salman, Florin Ionescu, and Riad Taha Al-Kasasbeh. "Modelling and simulation of a SCARA robot using solid dynamics and verification by MATLAB/Simulink." International Journal of Modelling, Identification and Control 15, no. 1 (2011): 28-38.

[5] Federspil, Philipp A., Urban W. Geisthoff, Dominik Henrich, and Peter K. Plinkert. "Development of the first force-controlled robot for otoneurosurgery." The Laryngoscope 113, no. 3 (2003): 465-471.

[6] Vijayakumar, T. "FLEXIBLE ROBOTIC ELECTRONIC SKIN WITH HIGH SENSITIVITY SENSOR ARRAYS." Journal of Electronics 1, no. 01 (2019): 43-51.

[7] Siciliano, Bruno, Lorenzo Sciavicco, Luigi Villani, and Giuseppe Oriolo. Robotics: modelling, planning and control. Springer Science \& Business Media, 2010.

[8] Sciavicco, Lorenzo, and Bruno Siciliano. Modelling and control of robot manipulators. Springer Science \& Business Media, 2012.

[9] Manoharan, Samuel, and Narain Ponraj. "PRECISION IMPROVEMENT AND DELAY REDUCTION IN SURGICAL TELEROBOTICS." Journal of Artificial Intelligence 1, no. 01 (2019): 28-36.

[10] Bu, Yin, Wenhe Liao, Wei Tian, Jin Zhang, and Lin Zhang. "Stiffness analysis and optimization in robotic drilling application." Precision Engineering 49 (2017): 388-400.

[11] Zubrzycki, Jarosław, Antoni Świć, and Marek Opielak. "Modelling of dynamic system characteristics of deep hole drilling process with tools about flexible stifness." In Applied Mechanics and Materials, vol. 613, pp. 333-339. Trans Tech Publications, 2014.

[12] Potthast, Christian, Jens Twiefel, and Jörg Wallaschek. "Modelling approaches for an ultrasonic percussion drill." Journal of Sound and Vibration 308, no. 3-5 (2007): 405-417.

[13] Sedano, Javier, Emilio Corchado, Leticia Curiel Herrera, José Ramón Villar Flecha, and Pedro Miguel Bravo. "The application of a two-step AI model to an automated pneumatic drilling process." International Journal of Computer Mathematics 86, no. 10-11 (2009): 1769-1777.

ISSN: 2582-3051 
Journal of Electrical Engineering and Automation (EEA) (2019)

Vol.01/ No. 02

Pages: 103-112

https://www.irojournals.com/iroeea

DOI: https://doi.org/10.36548/jeea.2019.2.005

[14] Adam, Asrul, Amar Faiz Zainal Abidin, Zuwairie Ibrahim, Abdul Rashid Husain, Zulkifli Md Yusof, and Ismail Ibrahim. "A particle swarm optimization approach to Robotic Drill route optimization." In 2010 fourth Asia international conference on mathematical/analytical modelling and computer simulation, pp. 60-64. IEEE, 2010.

[15] Wang, Zhanxi, Jing Bai, Xiaoyu Zhang, Xiansheng Qin, Xiaoqun Tan, and Yali Zhao. "Base detection research of drilling robot system by using visual inspection." Journal of Robotics 2018 (2018).

[16] Liu, Fei, Mitja Trkov, Jingang Yi, and Nenad Gucunski. "Modeling of pure percussive drilling for autonomous robotic bridge decks rehabilitation." In 2013 IEEE International Conference on Automation Science and Engineering (CASE), pp. 1063-1068. IEEE, 2013.

ISSN: 2582-3051 